\title{
Morfometria do aparelho genital e resposta superovulatória de coelhas suplementadas com geleia real
}

\author{
[Morphometry of the genital tract and superovulatory response in rabbits \\ supplemented with royal jelly] \\ P.A. Dutra, L.P. Barbosa*, A.L.A. Santana, C.S. Aguiar, R.S. Souza, B.M. Cardoso Neto, \\ M.L. Araújo, R.C.S.A. Araújo
}

Universidade Federal do Recôncavo da Bahia - Cruz das Almas, BA

\begin{abstract}
RESUMO
Avaliou-se o efeito da suplementação com geleia real sobre a morfometria do aparelho genital, resposta superovulatória e qualidade embrionária de coelhas. Trinta e seis fêmeas foram distribuídas em quatro grupos (G), sendo: $\mathrm{G} 1(\mathrm{n}=9)$ formado por animais não suplementados com geleia real, e G2, G3 e G4 ( $\mathrm{n}=9$ em cada grupo) por animais suplementados com 10, 20 e 40mg/dia de geleia real. A superovulação consistiu na aplicação de 40UI de gonadotrofina coriônica equina, seguida por 40UI de gonadotrofina coriônica humana, via intramuscular, 48 horas após, e submetidas à cobrição natural. Os animais foram sacrificados, e os embriões coletados 72 horas após a cópula. Não houve diferença estatística entre tratamentos para as variáveis analisadas. O peso médio do aparelho genital foi de $10,88 \pm 0,38 \mathrm{~g}$; dos ovários - direito e esquerdo -, 0,28 $\pm 0,02 \mathrm{~g}$; e o índice gonadossomático, $0,02 \pm 0,0 \mathrm{~g}$. O número médio de estruturas totais recuperadas foi de $9,2 \pm 1,4$; de embriões viáveis, $8,7 \pm 1,4$; e de degenerados, $0,5 \pm 0,2$. Dos embriões viáveis, $5,6 \pm 0,8$ foram classificados como grau I; $2,3 \pm 0,5$, como grau II; e $0,8 \pm 0,2$, como grau III. A suplementação com geleia real na dose de até $40 \mathrm{mg} /$ dia não apresentou efeito estimulador sobre o aparelho genital e a qualidade embrionária de coelhas.
\end{abstract}

Palavras-chave: coelho, embrião, reprodução, superovulação

\begin{abstract}
The purpose of this paper was to assess the effect of supplementation of royal jelly on the morphometry of the genital tract, superovulatory response and embryonic quality in adult rabbits. 36 rabbits were distributed in four groups $(G)$, as follows: G1 (n=9): no supplementation with royal jelly, G2, 3 and 4 $(n=9)$ : supplementation with 10, 20 and 40mg/day of royal jelly. The superovulatory protocol consisted in the application of a dose of 40UI of Equine Chorionic Gonadotrophin, followed by a dose of UI of Human Chorionic Gonadotrophin, intramuscularly, 48 hours later, and submitted to natural cover. The animals were euthanasiated and the embryos collected 72 hours after copulation. There was no statistical difference for the analyzed variables $(P>0.05)$. The average weight for the female genital tract was $10.89 \pm 0.38 \mathrm{~g}$; the average weight of right and left ovaries was $0.28 \pm 0.02 \mathrm{~g}$ and the average gonadosomatic index rate was $0.02 \pm 0.0 \mathrm{~g}$. The number of total recovered structures was $9.2 \pm 1.4$. The average number of viable embryos was $8.7 \pm 1.4$ and of degenerated embryos was $0.5 \pm 0.2$. Viable embryos were morphologically classified as degree I: $5.6 \pm 0$.8; degree II: $2.3 \pm 0.5$; degree III: $0.8 \pm 0.2$. Royal jelly did not present stimulatory effect on organs related to the reproduction of rabbits, nor was it effective to improve their embryonic quality at dosages of up to $40 \mathrm{mg}$ of in natura royal jelly.
\end{abstract}

Keywords: embryo, rabbit, reproduction, superovulation

Recebido em 21 de novembro de 2011

Aceito em 12 de dezembro de 2012

*Autor para correspondência (corresponding author)

E-mail: larissa@ufrb.edu.br 


\section{INTRODUÇÃO}

A geleia real é uma substância produzida pelas glândulas mandibulares e hipofaríngeas das abelhas operárias e serve de alimento para todas as larvas nos primeiros três dias de vida. É o único alimento para a abelha rainha durante todo seu ciclo de vida (Schmidt, 1996), promovendo nesta o aumento da massa corporal e o desenvolvimento de estruturas relacionadas à reprodução (Ohashi et al., 1997). Trata-se de uma emulsão de proteínas, açúcares, lipídios, água, elementos minerais e outras substâncias ainda não identificadas (Nagai e Inoue, 2004). Esse produto vem sendo difundido e utilizado como alimento funcional, em razão de sua ampla variedade de atividades farmacológicas. $\mathrm{Na}$ reprodução, essa secreção tem sido usada, entre outras finalidades, para melhorar a fertilidade em codornas (Csuka et al., 1978), aumentar a libido em homens e melhorar os parâmetros reprodutivos em coelhos (Khattab et al., 1989), ovelhas (Husein et al., 1999) e camundongos (Barbosa et al., 2009; Morais et al., 2009).

Os mecanismos exatos envolvidos na ação da geleia real sobre as funções reprodutivas ainda não foram totalmente elucidados, mas sabe-se que ela pode exercer seus efeitos por meio de substâncias semelhantes a hormônios ou por alterações nas secreções hormonais nos indivíduos que a recebem (Kridli e Al-Khetib, 2006). A maioria dos estudos que exploraram os efeitos biológicos da geleia real, em outros organismos além das abelhas, foi desenvolvida com animais experimentais. Alguns foram utilizados em experimentos visando posterior aplicação em seres humanos, entre estes estão os coelhos (Elnagar et al., 2010). De maneira benéfica, a comprovação científica dos efeitos da geleia real na reprodução de animais experimentais pode ampliar as possibilidades de estudos referentes aos seus efeitos em seres humanos, em animais elites de produção, bem como para conservação de espécimes silvestres em extinção ou com problemas de reprodução em cativeiro.

Dessa forma, objetivou-se avaliar o efeito da suplementação com geleia real in natura sobre a morfometria do aparelho genital, a resposta superovulatória e a qualidade embrionária de coelhas adultas.

\section{MATERIAL E MÉTODOS}

Foram utilizadas 36 coelhas das raças Califórnia e Nova Zelândia, selecionadas após a desmama, com 30 dias de idade. Os animais foram mantidos dentro de gaiolas suspensas de arame galvanizado, providas de comedouros e bebedouros, recebendo água, ração comercial (Primor®, BA - Brasil) (composição: farelo de trigo, farelo de milho, farelo de soja, casca de arroz, calcário moído, premix vitamínico mineral e cloreto de sódio) e rami (Boehmeria nívea) ad libitum.

As fêmeas foram distribuídas aleatoriamente em quatro grupos (G). As do G1 (n=9) não receberam suplementação com geleia real (grupo controle); e as do G2 (n=9), G3 (n=9) e G4 (n=9) receberam suplementação com 10, 20 e 40mg/dia de geleia real in natura, respectivamente.

A geleia real foi administrada por via oral, com o auxílio de seringa desprovida de agulha, e os animais do grupo controle receberam água por via oral. Os animais experimentais não foram contidos para a administração da suplementação.

Tabela 1. Composição bromatológica da geleia real

\begin{tabular}{lc}
\hline Ingrediente & Valor (\%) \\
\hline Água & 60 \\
Proteína & $12-18$ \\
Carboidratos & $13-25$ \\
Lipídeos & 5 \\
Vitaminas (B1, 2, 3, 5, 6, 8, 9, 12, A, C, D, E e hormônios sexuais) & 3 \\
Sais minerais (Mg, Fe, S, Zn, Cu, Mn) & 1 \\
\hline
\end{tabular}

Geleia real in natura (Cia. do Mel®, BA - Brasil). 
A geleia real (Cia. do Mel®, BA - Brasil) (Tab. 1) foi diluída previamente em água destilada, armazenada em microtubos de polietileno graduado e estocada em freezer a $-20^{\circ} \mathrm{C}$ (Kamakura et al., 2001).

A suplementação foi iniciada 24 horas após o desmame das fêmeas com 30 dias de idade, diariamente às sete horas, até a desmama do segundo parto, totalizando um período de 11 meses consecutivos. Após 30 dias do segundo parto, as fêmeas foram submetidas à superovulação e à cobertura natural. O protocolo superovulatório consistiu na aplicação de uma dose de 40UI de gonadotrofina coriônica equina (eCG), por via intramuscular (IM), 24 horas após a desmama, e, 48 horas após, 40UI de gonadotrofina coriônica humana (hCG) IM. Em seguida, foram submetidas a três cobrições naturais, em intervalos de oito horas. Os embriões foram coletados 72 horas após a cópula.

As coelhas foram pesadas em balança digital com cinco dígitos (Filizola $\left.{ }^{\circledR}\right)$, e logo após, sacrificadas, utilizando-se pentobarbital sódico, $27 \mathrm{mg} / \mathrm{kg}$, intravenoso (IV), para sedação e, posteriormente, cloreto de potássio, para o sacrifício, respeitando-se a resolução $\mathrm{n}^{\circ} 714$, de 20 de junho de 2002, sobre os procedimentos e métodos de eutanásia de animais, recomendados pelo Conselho Federal de Medicina Veterinária. Após sacrifício, foram realizadas uma incisão na região abdominal e a abertura do peritônio para a remoção dos intestinos, com o auxílio de uma pinça, e retirou-se o tecido adiposo que envolvia o aparelho genital.

O aparelho genital foi pesado em balança digital de precisão (Radwag®), utilizando-se paquímetro (Messen®). Fez-se, então, a avaliação das seguintes variáveis morfométricas: comprimento e diâmetro da tuba uterina, comprimento e diâmetro dos cornos uterinos, largura e altura dos ovários, procedendo-se, em seguida, à pesagem deles, para posterior cálculo do índice gonadossomático (IGS), IGS $=[$ (peso das gônadas/peso total) x 100].

Os ovários foram levados ao estereomicroscópio, com aumento de 20x, para contagem do número de folículos e de corpos lúteos. Os dois cornos uterinos foram separados e lavados com PBS (Dulbecco's phosphate saline) em temperatura ambiente, com auxílio de um escalpe número 23. Foram realizadas três lavagens por corno uterino com 20mL de PBS em temperatura ambiente no sentido ápice do corno para a base. Os cornos uterinos foram levemente massageados, e o efluente recolhido em placas de petri quadriculadas. Após esse procedimento, os embriões foram identificados e classificados, com o auxílio de um estereomicroscópio com aumento de 40x, quanto ao estágio de desenvolvimento e ao aspecto morfológico, segundo a classificação proposta pela Sociedade Internacional de Transferência de Embriões (Stringfellow e Givens, 2010). A taxa de recuperação embrionária foi calculada conforme a fórmula: [(número de estruturas coletadas/ número de corpos lúteos totais) x 100] (Boiti et al., 1996).

Foi usado um delineamento em blocos ao acaso, e as análises estatísticas foram realizadas com a utilização do programa computacional SAS (2004) na análise de variância pelo procedimento GLM, com 5\% de probabilidade.

A suplementação das coelhas com $0,10,20 \mathrm{e}$ $40 \mathrm{mg}$ de geleia real in natura não influenciou (P>0,05) nos pesos do aparelho genital e dos ovários e no índice gonadossomático (Tab. 2).

A atividade estrogênica apresentada pela geleia real (Mishima et al., 2005; Suzuki et al., 2008) nas doses utilizadas, provavelmente, não foi suficiente para promover diferenças no desenvolvimento do aparelho genital das fêmeas e, consequentemente, em seus pesos. O IGS corresponde à proporção do peso corporal alocada em ambos os ovários, sendo um dado auxiliar para a observação da influência da geleia real sobre o aparelho genital das fêmeas. O valor médio encontrado para o IGS nos quatro grupos foi de $0,02 \pm 0,0 \%$.

Não houve diferença $(\mathrm{P}>0,05)$ entre os grupos para morfometria ovariana, por meio das mensurações de largura, comprimento e altura dos ovários direito e esquerdo, independentemente das concentrações de geleia real utilizadas (Tab. 3). 
Tabela 2. Peso corporal, do aparelho genital, dos ovários e índice gonadossomático (IGS) de coelhas suplementadas com geleia real in natura

\begin{tabular}{lccccc}
\multicolumn{1}{c}{ Variável } & $\begin{array}{c}\mathrm{G} 1 \\
(0 \mathrm{mg})\end{array}$ & $\begin{array}{c}\mathrm{G} 2 \\
(10 \mathrm{mg})\end{array}$ & $\begin{array}{c}\mathrm{G} 3 \\
(20 \mathrm{mg})\end{array}$ & $\begin{array}{c}\mathrm{G} 4 \\
(40 \mathrm{mg})\end{array}$ & Média \\
\hline Peso corporal $(\mathrm{g})$ & $3171 \pm 110$ & $2910 \pm 58$ & $2821 \pm 57$ & $3100 \pm 90$ & $3003 \pm 46$ \\
Peso do aparelho genital $(\mathrm{g})$ & $11,14 \pm 0,86$ & $12,06 \pm 0,71$ & $9,70 \pm 0,46$ & $10,62 \pm 0,83$ & $10,88 \pm 0,38$ \\
Peso do ovário direito $(\mathrm{g})$ & $0,29 \pm 0,02$ & $0,27 \pm 0,02$ & $0,27 \pm 0,01$ & $0,34 \pm 0,05$ & $0,29 \pm 0,02$ \\
Peso do ovário esquerdo $(\mathrm{g})$ & $0,27 \pm 0,02$ & $0,27 \pm 0,02$ & $0,27 \pm 0,02$ & $0,34 \pm 0,04$ & $0,28 \pm 0,02$ \\
IGS (\%) & $0,01 \pm 0,0$ & $0,01 \pm 0,0$ & $0,01 \pm 0,0$ & $0,02 \pm 0,0$ & $0,02 \pm 0,0$ \\
\hline
\end{tabular}

G1= grupo controle, que recebeu água destilada; $\mathrm{G} 2=$ suplementação com $10 \mathrm{mg}$ de geleia real; $\mathrm{G} 3=$ suplementação com 20mg de geleia real e G4= suplementação com 40mg de geleia real.

Não houve diferença significativa entre os tratamentos $(\mathrm{P}>0,05)$.

Tabela 3. Morfometria ovariana de coelhas suplementadas com geleia real in natura

\begin{tabular}{lccccc}
\hline \multicolumn{1}{c}{$\begin{array}{c}\text { Variável } \\
(\mathrm{cm})\end{array}$} & $\begin{array}{c}\mathrm{G} 1 \\
(0 \mathrm{mg})\end{array}$ & $\begin{array}{c}\mathrm{G} 2 \\
(10 \mathrm{mg})\end{array}$ & $\begin{array}{c}\mathrm{G} 3 \\
(20 \mathrm{mg})\end{array}$ & $\begin{array}{c}\mathrm{G} 4 \\
(40 \mathrm{mg})\end{array}$ & Média \\
\hline Largura do ovário direito & $0,44 \pm 0,0$ & $0,38 \pm 0,0$ & $0,42 \pm 0,0$ & $0,44 \pm 0,0$ & $0,42 \pm 0,0$ \\
Largura do ovário esquerdo & $0,47 \pm 0,0$ & $0,41 \pm 0,0$ & $0,36 \pm 0,0$ & $0,44 \pm 0,0$ & $0,42 \pm 0,0$ \\
Comprimento do ovário direito & $1,57 \pm 0,1$ & $1,62 \pm 0,0$ & $1,55 \pm 0,1$ & $1,71 \pm 0,1$ & $1,61 \pm 0,0$ \\
Comprimento do ovário esquerdo & $1,56 \pm 0,1$ & $1,58 \pm 0,0$ & $1,50 \pm 0,0$ & $1,60 \pm 0,1$ & $1,56 \pm 0,0$ \\
Altura do ovário direito & $0,17 \pm 0,0$ & $0,16 \pm 0,0$ & $0,30 \pm 0,0$ & $0,20 \pm 0,0$ & $0,21 \pm 0,0$ \\
Altura do ovário esquerdo & $0,17 \pm 0,0$ & $0,17 \pm 0,0$ & $0,26 \pm 0,0$ & $0,20 \pm 0,0$ & $0,20 \pm 0,0$ \\
\hline
\end{tabular}

G1= grupo controle, que recebeu água destilada; $\mathrm{G} 2=$ suplementação com 10mg de geleia real; G3= suplementação com 20mg de geleia real e G4= suplementação com 40mg de geleia real.

Não houve diferença significativa entre os tratamentos $(\mathrm{P}>0,05)$.

A geleia real possui importância fundamental para a diferenciação das castas e para a determinação das características exclusivas à abelha rainha, como o aumento da massa corporal, a longevidade e o desenvolvimento de estruturas relacionadas à reprodução (Ohashi et al., 1997). Dessa forma, esperava-se um maior desenvolvimento dos ovários das coelhas suplementadas com geleia real in natura, sobretudo em razão da atividade esteroidogênica presente na geleia real (Kridli e Al-Khetid, 2006), o que poderia influenciar positivamente na reprodução das coelhas, com o aumento da função ovariana.

Não houve diferença para o comprimento e o diâmetro da tuba uterina e dos cornos uterinos com a suplementação de geleia real in natura $(\mathrm{P}>0,05)$ (Tab. 4).

Tabela 4. Morfometria da tuba uterina e dos cornos uterinos de coelhas suplementadas com geleia real in natura

\begin{tabular}{llllll}
\hline \multicolumn{1}{c}{$\begin{array}{c}\text { Variável } \\
(\mathrm{cm})\end{array}$} & \multicolumn{1}{c}{$\mathrm{G} 1$} & \multicolumn{1}{c}{$\mathrm{G} 2$} & \multicolumn{1}{c}{$\mathrm{G} 3$} & \multicolumn{1}{c}{$\mathrm{G} 4$} & Média \\
$(0 \mathrm{mg})$ & $(10 \mathrm{mg})$ & \multicolumn{1}{c}{$(20 \mathrm{mg})$} & \multicolumn{1}{c}{$(40 \mathrm{mg})$} & \\
\hline Comprimento da tuba uterina & $9,92 \pm 0,5$ & $9,40 \pm 0,7$ & $9,75 \pm 0,3$ & $11,11 \pm 0,4$ & $10,06 \pm 0,2$ \\
Diâmetro da tuba uterina & $1,77 \pm 0,2$ & $1,76 \pm 0,2$ & $1,88 \pm 0,2$ & $2,11 \pm 0,2$ & $1,88 \pm 0,1$ \\
Comprimento dos cornos uterinos & $13,35 \pm 1,2$ & $12,32 \pm 0,6$ & $12,05 \pm 1,6$ & $10,58 \pm 1,6$ & $12,07 \pm 0,4$ \\
Diâmetro dos cornos uterinos & $0,52 \pm 0,0$ & $0,58 \pm 0,0$ & $0,53 \pm 0,0$ & $0,58 \pm 0,0$ & $0,55 \pm 0,0$ \\
\hline
\end{tabular}

G1= grupo controle, que recebeu água destilada; G2= suplementação com 10mg de geleia real; G3= suplementação com 20mg de geleia real; $\mathrm{G} 4=$ suplementação com 40mg de geleia real.

Não houve diferença significativa entre os tratamentos $(\mathrm{P}>0,05)$.

As doses utilizadas de geleia real não foram eficientes em promover desenvolvimento do aparelho genital das fêmeas, portanto mostraramse incapazes de alterar parâmetros morfométricos da tuba uterina e dos cornos uterinos. A quantidade de hormônios esteroides (Hidaka et al., 2006) ou de substâncias semelhantes aos hormônios, como o ácido 10-hidroxi-trans-2decenoico, ácido 10-hidroxidecanoico, ácido trans-2-decenoico e 24-metilenocolesterol, que 
estão presentes na geleia real e exibem atividade estrogênica (Suzuki et al., 2008), provavelmente foram insuficientes em causar essas alterações em coelhas.

Para resposta superovulatória, não foi encontrada diferença significativa $(\mathrm{P}>0,05)$ entre os grupos, por meio das avaliações do número de folículos dos ovários direito e esquerdo, do número de corpos lúteos dos ovários direito e esquerdo, do número total de corpos lúteos e das estruturas totais recuperadas (Tab. 5).

Tabela 5. Resposta superovulatória de coelhas suplementadas com geleia real in natura

\begin{tabular}{lccccc}
\multicolumn{1}{c}{ Variável } & $\mathrm{G} 1$ & $\mathrm{G} 2$ & $\mathrm{G} 3$ & $\mathrm{G} 4$ & Média \\
& $(0 \mathrm{mg})$ & $(10 \mathrm{mg})$ & $(20 \mathrm{mg})$ & $(40 \mathrm{mg})$ & \\
\hline Número de folículos no ovário direito & $23,0 \pm 3,6$ & $26,0 \pm 6,6$ & $15,0 \pm 2,4$ & $19,0 \pm 3,1$ & $20,9 \pm 1,9$ \\
Número de folículos no ovário esquerdo & $19,0 \pm 2,9$ & $24,0 \pm 6,8$ & $17,0 \pm 1,7$ & $14,0 \pm 4,3$ & $18,8 \pm 1,8$ \\
Número de corpos lúteos no ovário direito & $6,0 \pm 1,9$ & $7,0 \pm 1,8$ & $7,8 \pm 1,2$ & $5,0 \pm 3,5$ & $6,8 \pm 0,8$ \\
Número de corpos lúteos no ovário esquerdo & $8,0 \pm 1,8$ & $7,0 \pm 0,5$ & $5,0 \pm 0,8$ & $7,0 \pm 4,4$ & $7,2 \pm 0,6$ \\
Número total de corpos lúteos & $14,0 \pm 3,7$ & $14,0 \pm 2,2$ & $13,0 \pm 1,7$ & $13,0 \pm 6,6$ & $14,0 \pm 1,2$ \\
\hline
\end{tabular}

G1= grupo controle, que recebeu água destilada; G2= suplementação com 10mg de geleia real; G3= suplementação com 20mg de geleia real; G4= suplementação com 40mg de geleia real.

Não houve diferença significativa entre os tratamentos $(\mathrm{P}>0,05)$.

O número de folículos encontrado (Tab. 5) nos ovários direito e esquerdo foi maior que o encontrado por Andreazzi et al. (2006), que observaram 2,0 folículos no ovário direito e 3,1 no ovário esquerdo de coelhas Nova Zelândia, superovuladas com 40UI de eCG. O número de corpos lúteos do ovário direito foi de 11,7 e de 11,6 no ovário esquerdo, sendo a taxa de recuperação de $38 \%$, enquanto esta pesquisa obteve taxa de recuperação média de $57 \pm 6,5 \%$.

Não foi encontrada diferença significativa ( $\mathrm{P}>0,05)$ para número de embriões viáveis, degenerados e embriões graus I, II e III, independentemente da suplementação utilizada (Tab. 6).

Tabela 6. Qualidade embrionária de coelhas superovuladas suplementadas com geleia real in natura

\begin{tabular}{lccccc}
\multicolumn{1}{c}{ Variável } & G1 $(0 \mathrm{mg})$ & G2 $(10 \mathrm{mg})$ & G3(20mg) & G4(40mg) & média \\
\hline Embriões viáveis & $7,8 \pm 3,8$ & $10,4 \pm 2,9$ & $8,4 \pm 1,8$ & $11,6 \pm 2,6$ & $8,7 \pm 1,4$ \\
Embriões degenerados & $0,0 \pm 0,0$ & $0,6 \pm 0,3$ & $1,5 \pm 2,7$ & $0,4 \pm 0,5$ & $0,5 \pm 0,2$ \\
Embriões grau I & $4,3 \pm 1,7$ & $6,0 \pm 1,8$ & $4,4 \pm 3,1$ & $9,5 \pm 5,7$ & $5,6 \pm 0,8$ \\
Embriões grau II & $2,7 \pm 1,7$ & $2,3 \pm 1,1$ & $2,6 \pm 2,3$ & $2,1 \pm 2,9$ & $2,3 \pm 0,5$ \\
Embriões grau III & $0,8 \pm 0,5$ & $2,1 \pm 0,7$ & $1,4 \pm 1,3$ & $0,0 \pm 0,0$ & $0,8 \pm 0,2$ \\
Estruturas totais & $7,8 \pm 3,6$ & $11 \pm 3,0$ & $9,9 \pm 1,8$ & $12 \pm 2,7$ & $9,2 \pm 1,4$ \\
\hline
\end{tabular}

G1= grupo controle, que recebeu água destilada; G2= suplementação com 10mg de geleia real; G3= suplementação com 20mg de geleia real; G4= suplementação com 40mg de geleia real.

Não houve diferença significativa entre os tratamentos $(\mathrm{P}>0,05)$.

Os resultados encontrados corroboram o estudo realizado por Barbosa et al. (2009), que também não encontraram diferença entre o número total de estruturas viáveis por coleta de fêmeas de camundongos superovuladas e suplementadas com geleia real, sendo encontradas 15,6; 20,2 e 17,8 estruturas viáveis para os animais do grupo controle e suplementados com 0,5 e $1,0 \mathrm{mg}$ de geleia real, respectivamente.

Andreazzi et al. (2006) encontraram, em coelhas superovuladas, número de embriões degenerados de $0,2 \pm 0,9$ no grupo suplementado com óleo de soja, dados que se assemelham aos do presente trabalho, enquanto Barbosa et al.
(2009) verificaram $8,4 \pm 4,3 ; 9,3 \pm 7,3 ; 5,2 \pm 2,4$ embriões degenerados para fêmeas de camundongos superovuladas do grupo controle e suplementadas com 0,5 e $1,0 \mathrm{mg}$ de geleia real, respectivamente. $\mathrm{O}$ número de embriões viáveis também corroboram os achados de Barbosa et al. (2009).

Para qualidade morfológica dos embriões viáveis, Barbosa et al. (2009) também não encontraram diferenças para embriões graus I, II e III, com valores de 9,25; 2,75; 3,62 (grupo controle), de 10,$69 ; 3,92 ; 5,61$ (grupo que recebeu $0,5 \mathrm{mg}$ de geleia real) e de 10,$22 ; 2,77 \mathrm{e}$ 4,88 (grupo que recebeu $1,0 \mathrm{mg}$ de geleia real). 


\section{CONCLUSÕES}

A suplementação de geleia real in natura, administrada por um período de 11 meses, nas doses de 10, 20 e 40mg/dia, não apresenta ação estimuladora sobre os órgãos relacionados com a reprodução de coelhas, nem foi eficiente em melhorar a resposta superovulatória e a qualidade embrionária desses animais.

\section{REFERÊNCIAS}

ANDREAZZI, M.A.; RIGOLON, L.P.; CAVALIERI, F.L.B. et al. Superovulação em coelhas alimentadas com ração, contendo diferentes fontes de óleos vegetais. Acta Sci. Anim., v.28, p.295-300, 2006.

BARBOSA, L.P.; RODRIGUES, M.V.; BALARINI, M.K. et al. Qualidade embrionária de camundongos (Mus musculus) suplementados com geleia real. Rev. Bras. Saúde Prod. Anim., v.10, p.146-152, 2009.

BOITI, C.; CANALI, C.; MONACI, M. et al. Effect of postpartum progesterone levels on receptivity ovarian response, embryo quality and development in rabbits. In: WORLD CONGRESS OF ANIMAL FEEDING, 6., 1996, Toulouse. Proceedings... Toulouse: ACAF. 1996. p.45-49.

CSUKA, J.; BAUMGARTNER, J.; DUBAY, J. The effect of Royal jelly on some reproductive characters of Japanese quail. Zivocisna Vyroba, v.23, p.395-400, 1978.

ELNAGAR, S.A.; ELGHALID, O.A.; ABDELHADY, M.A. Royal jelly: can it reduce physiological strain of growing rabbits under Egyptian summer conditions? Anim. Consort., v.4, p.1547-1552, 2010 .

HIDAKA, S.; OKAMOTO, Y.; UCHIYAMA, S. et al. Royal jelly prevents osteoposis in rats: Beneficial effects in ovariectomy model and in bone tissue culture model. $e C A M, \mathrm{v} .3$, p.339-348, 2006.

HUSEIN, M.Q.; KRIDLI, R.T.; HUMPHREY, W.D. Effect of royal jelly on estrus synchronization and pregnancy rate of ewes using flourogestone acetate sponges. J. Anim. Sci., v.77, p.431, 1999.
KAMAKURA, M.; FUKUDA, T.; FUKUSHIMA, M.; YONEKURA, M. Storage-dependent degradation of 57-kDa protein in Royal Jelly: a Possible Marker for Freshness. Biosci. Biotechnol. Biochem., v.65, p.277284, 2001.

KHATTAB, M.M.; RADWAN, A.A.; AFIFI, E.A. Physiological effect of royal jelly on female reproductive capacity in rabbits. In: INTERNATIONAL CONFERENCE ON APICULTURE TROPICAL CLIMATES, 4., 1989, Cairo. Proceed ..., Cairo, 1989.

KRIDLI, R.T.; AL-KHETIB, S.S. Reproductive responses in ewew treates whit eCG or increasing doses of royal jelly. Anim. Reprod. Sci., v.92, p.75-85, 2006.

MISHIMA, S.; SUZUKI, K.M.; ISOHAMA, Y. et al. Royal jelly has estrogenic effects in vitro and in vivo. J. Ethnopharmacol., v.101, p.215-20, 2005.

MORAIS, A.C.T.; BARBOSA, L.P.; NEVES, M.M. et al. Parâmetros morfosifiológicos testiculares de camundongos (Mus musculus) suplementados com geleia real. Arq. Bras. Med. Vet., v.61. p.110-118, 2009.

NAGAI, T.; INOUE, R. Preparation and the functional properties of water and alkaline extract of royal jelly. Food Chem., v.84, p.181-186, 2004.

OHASHI, K.; NATORI, S.; KUBO, T. Change in the mode of gene expression of the hypopharyngeal gland cells with an age-dependent role change of the worker honeybee Apis mellifera L. J. Biochem., v.249, p.797802, 1997

SAS INSTITUTE. SAS/STAT® user's guide. Versão 9.1.3. Cary: 2004. (CD-ROM).

SCHMIDT, J.O. Bee products: chemical composition and application. MIZRAHI, H., LENSKY, Y. (Eds.), Bee Products: Properties, Applications and Apitherapy. New York: Plenum, 1996. p.15-26.

STRINGFELLOW, D.A.; GIVENS, M.D. Manual da Sociedade Internacional de Transferência de Embriões (IETS). 4.ed, p.8-13, 2010.

SUZUKI, K.M.; ISOHAMA, Y.; MARUYAMA, H. et al. Estrogenic activities of fatty acids and a sterol isolated from Royal jelly. Evidence-basead complementary and alternative medicine. eCAM., v.5, p.295-302, 2008. 